\title{
Pemetaan kompetensi pedagogik dalam keterkaitan dimensi pengetahuan pedagogik dan profil karakteristik awal
}

\author{
Ratnawati Susanto*) \\ Universitas Esa Unggul
}

\begin{tabular}{l} 
Article Info \\
\hline Article history: \\
Received Mar $30^{\text {th }}, 2021$ \\
Revised Apr $19^{\text {th }}, 2021$ \\
Accepted May $25^{\text {th }}, 2021$ \\
\hline
\end{tabular}

\section{Keyword:}

Kompetensi pedagogik

Mutu pendidikan

Kompetensi guru

\begin{abstract}
Keberhasilan pembelajaran dipengaruhi oleh kemampuan serta keterampilan guru dalam mengelola proses pembelajaran dengan terus meningkatkan kompetensi pndagogik yang optimal. Tujuan penelitian ini menganalisis pemetaan kompetensi pedagogik dalam keterkaitkan dimensi pengetahuan pedagogik dan profil karakteristik awal guru. Responden dalam penelitian ini terdiri dari 265 guru. Metode penelitian kuantitatif dengan survey. Pengumpulan data dilakukan secara online dengan menggunakan platfrom google form. Instrumen yang digunakan berupa formulir kuesioner untuk mengukur kompetensi pedagogik, pengetahuan pedagogik serta profil karakteristik guru yang telah teruji kevalidan dan reliabilitasnya sehingga layak digunakan. Analisis data menggunakan deskriptif analisis, regresi sederhana, serta analisis jaringan. Hasil penelitian menujukkan bahwa kompetensi pedagogik, pengetahuan pedagogik dan profil karakteristik awal guru berada pada kategori sangat baik, selanjutnya pengetahuan pedagogik berkontribusi sebesar $62,1 \%$ terhadap kompetensi pndagogik, serta profil karakteristik awal berkontribusi sebesar $49,7 \%$ terhadap kompetensi pedagogik guru, dari analisis jaringan bahwa pengetahuan pedagogik dan profil karakteristik awal memiliki hubungan yang kuat untuk membangun kompetensi pedagogik. Untuk selanjutnya diperlukan pengembangan dan pelatihan dalam mengoptimalkan kompetensi pedagogik guru dalam rangkan mengembangkan mutu pendidikan Indonesia.
\end{abstract}

(C) 2021 The Authors. Published by IICET.

This is an open access article under the CC BY-NC-SA license

(https://creativecommons.org/licenses/by-nc-sa/4.0)

\section{Corresponding Author:}

Ratnawati Susanto,

Universitas Esa Unggul

Email: ratnawati@esaunggul.ac.id

\section{Pendahuluan}

Guru sebagai agen pembelajaran berperan dalam meningkatkan dan mengembangkan mutu pendidikan formal berperan strategis terhadap pembangunan pendidikan di Indonesia (Saragih, 2008; Siregar, 2020). Oleh karena itu guru bertanggungjawab dalam penyelenggaraan proses pembelajaran dengan baik serta perlu menempatkan profesi guru dengan keunggulan kemampuan pedagogik sebagai ciri profesi guru yang membedakan dengan profesi lainnya sesuai dengan Undang-Undang No 14 Tahun 2005 Guru dan Dosen. Rumusan ini menempatkan guru dalam fungsi transformasi yang membuat perubahan terhadap peningkatan mutu pendidikan nasional Hal ini menandai peran guru sebagai komponen yang sangat penting dalam Pendidikan nasional (Yesi, Rahayu, \& Wahyuni, 2021).

Melalui pendidikan berkualitas akan terbangun negara dengan Pendidikan unggul dan menciptakan generasi unggul serta berkarakter (Lalo, 2018). Namun berdasarkan fakta empiris yang terjadi profil guru dan 
pendidikan di Indonesia belum sepenuhnya optimal. Tidak dipungkiri bahwa kulitas guru dan pendidikan di Indonesia dalam kategori rendah, merujuk data UNESCO pada Global Education Monitoring Report (GEM) bahwa Indonesia menduduki urutan 10 dari 14 dari negara berkembang secara dunia, dan kemampuan mutu guru pada ranking ke-14 dari 14 negara yang sedang berkembang di dunia internasional (Antoninis et al., 2020; Mundy \& Manion, 2021; Ramberg, 2021). Kemudian berdasarkan Programme for International Student Assessment (PISA) tahun 2018 yang dilakukan pengujian kepada anak-anak sekolah berusia 15 tahun di 77 negara dengan jumlah partisipan 600 ribu murid sekolah, menunjukkan bahwa anak-anak di Indonesia rendah pada bidang literasi dasar membaca, berhitung dan sains, dimana skor kemampuan literasi membaca Indonesia ada di peringkat 72 dari 77 negara (Hopfenbeck et al., 2018; Vazquez-Lopez \& Huerta-Manzanilla, 2021).

Merujuk permasalahan pendidikan di Indonesia, maka perlu peningkatan memajukan mutu pendidikannya, maka guru berkualitas adalah syarat utama yang harus ditingkatkan terlebih dahulu melalui pengembangan kompetensi guru. Artinya dalam melaksanakan tugas dan fungsinya guru harus dibekali dan memiliki segenap keahlian, keterampilan, pengetahuan tertentu dalam menjalankan tugas profesinya. Kemampuan guru perlu diwujudkan dalam bentuk kompetensi pedagogik yang mencakup pengetahuan, keterampilan yang menyatu sebagai perangkat dalam melaksanakan tugas profesinal. Kompetensi menjadi kemampuan sekaligus otoritas guru dalam tugas profesi keguruannya. Berdasarkan Undang 14 Tahun 2005 terdapat rumusan mengenai penguasaan yang harus dimiliki guru yang mencakup kapasitas kepribadian, pedagogik, professional, dan sosial. Keempat kompetensi ini harus dimiliki oleh guru agar dapat melaksanakan dan mengelola pengalaman belajar yang menekankan pada unsur belajar tuntas dan bermakna.

Namun dari keempat kompetensi tersebut pada kompetensi pendagogi guru tergolong rendah dan perlu dikembangkan dengan lebih baik. Berdasarkan data Kementrian Kebudayaan Departemen Guru dan Tenaga Kependidikan (GTK) pada asesmen kompetensi guru (UKG) tahun 2020 untuk aspek pedagogik dan profesional (Astuti \& Jailani, 2020; Mutadi, Mudofir, \& Munadi, 2021). Rerata hasilUKG tahun 2020 berada pada nilai 53,02. Untuk kompetensi pedagogik rata-rata nasional sebesar 48,94 masih berada dibawah standar kompetensi minimal (SKM) nasional yaitu 55 (Jalinus \& Risfendra, 2020; Permadi, 2020). Sementara hasil tertinggi dari kemampuan pedagogik diraih oleh DI Yogyakarta $(56,91)$. Hal ini menunjukkan bahwa pada kompetensi pedagogik guru secara nasional masih rendah. Hasil dari ujian kompetensi ini dapat dijadikan evaluasi bagi guru secara nasional untuk dapat dilakukan perbaikan, pembinaan, pengembangan dan peningkatan pada aspek kompetensi pedagogiknya (Musfah, 2021; Prawira \& Nugraha, 2021).

Kompetensi pedagogik sangat penting dikembangkan karena menyangkut kemampuan guru dalam mengelola proses pembelajaran dimana keberhasilan belajar dipengaruhi oleh pengelolan pembelajaran yang dilakukan oleh guru (Maksum, 2010; Sudrajat, 2020). Kompetensi Pedagogik adalah pemahaman dan kemampuan dalam tindakan: (a) kemampuan melakukan identifikasi karakteristik belajar siswa , (b) memberi kesempatan partisipasi aktif siswa, (c) mengelola kelas dengan fokus karakteristik yang berbeda, (d) mengelola penyimpangan perilaku belajar, (e) mengelola potensi dan kekurangan, dan (f) melakukan tindakan edukatif humanis. Kompetensi pedagogik merepresentasikan kapasitas dan kapabilitas guru dalam pengelolaan proses pembelajaran dan berfungsi dalam mengoptimalkan potensi peserta didik melalui upaya membimbing dan memimpin anak didik dalam memperoleh pengalaman belajar . (Suhandani \& Julia, 2014; Susanto et al., 2020).

Pada pengembangan kompetensi pedagogik guru perlu memiliki dan menguasi segenap pengetahun pedagogik yang baik. Pengetahuan Pedagogik adalah tingkat pengetahuan guru mengenai konsep filsafat pendidikan, psikologi perkembangan dan teori belajar (Agustiani, 2015; Charoline, Lestari, Rahadian, \& Mahulette, 2020). Guru harus menguasai baik muatan disiplin ilmu, maupun muatan pedagogik, yang kemudian dikembangkan berdasarkan perkembangan ilmu pengetahuan dan teknologi terkini. Guru mampu memahami karakteristik mahasiswa dan mengenalinya dengan berbagai pendekatan, memahami materi baik dalam konten disiplin maupun pedagogis, menguasai pendekatan pembelajaran yang perencanaan dan pelaksanaannya meningkatkan pengetahuan peserta didik dan mengembangkan kemandirian peserta didik (Kienlin, Poitras, Stacey, Nytrøen, \& Kasper, 2021; Kumala, Susilo, \& Susanto, 2018).

Kemudian selain pengetahun pedagogik yang baik guru juga harus memiliki profil karakteristik awal guru yang baik pula. Profil karakteristik awal merupakan kemampuan mendasar guru yang mencakup: (a) kemampuan memaknai spiritualitas profesi atau makna nilai pekerjaan dalam dirinya, (b) kemampuan tindakan belajar, bertumbuh dan berkembang dalam kegiatan pengembangan diri dalam kemampuan literasi konten pengetahuan, pedagogikal dan teknologi, dan (c) tingkat kemampuan guru dalam mengelola perubahan perilaku belajar peserta didik. Guru harus mampu menginternalisasi dan mentransformasikan nilai kehidupan, baik keterampilan keras dan lunak (hard dan soft skill) serta pertumbuhan peserta didik, agar terciptanya pengalaman belajar secara bermakna dan memfasilitasi anak didik menjadi sosok generasi muda 
yang menguasai ilmu dan pengetahuan serta keunggulan teknologi. Mampu mendahulukan tanggung jawab daripada hak dan dapat mempertahankan hidup dan lingkungannya (Amalianita, Firman, \& Ahmad, 2021; Liaqat et al., 2021). Maka diperlukannya pemetaan kompetensi pedagogik melalui pengembangan aspek pengetahuan pedagogik serta porfil karakteristik awal guru agar terwujudnya kompetensi pedagogik guru yang optimal dalam rangka untuk meningkatkan mutu pendidikan di Indonesia. Penelitian ini bertujuan mengkaji serta menganalisis pemetaan kompetensi pedagogik dalam keterkaitanya dimensi pengetahuan pedagogik dan profil karakteristik guru.

\section{Metode}

Metode penelitian menggunakan pendekatan kuantitatif dengan jenis cross sectional survey untuk mendskripsikan dan menganalisis variabel kompetensi pedagogik guru serta keterkaitan dimensi pengetahuan pedagogik dan profil karakteristik awal guru. Responden dalam penelitian ini terdiri dari 265 guru yang tersebar diseluruh wilayah Indonesia. Penentuan Sampel menggunakan Probability sampling dengan jenis simple random sampling. Pengumpulan data melalui online dengan menggunakan platfrom google form yang diadiminstrasikan kepada guru. Instrumen yang digunakan berupa formulir kuesioner untuk mengukur kompetensi pedagogik, pengetahuan pedagogik serta profil karakteristik guru yang telah teruji kevalidan dan reliabilitasnya sehingga layak digunakan. Analisis data menggunakan deskriptif analisis, regresi sederhana, serta network analysis.

\section{Hasil dan Pembahasan}

Berdasarkan hasil pengolahan data dari 265 responden yang mengukur pada variabel kompetensi pedagogik, pengetahuan pedagogik dan profil karakteristik awal didapatkan informasi mengenai gambaran setiap varibaelnya, yang disajikan pada tabel 1 berikut.

Tabel 1. Deskripsi Data Variabel

\begin{tabular}{lrrr}
\hline & Kompetensi Pedagogik & Profil Karakteristik Awal & Pengetahuan Pedagogik \\
\hline Valid & 265 & 265 & 265 \\
Missing & 0 & 0 & 0 \\
Mean & 23.868 & 12.170 & 60.015 \\
Median & 25.000 & 12.000 & 63.000 \\
Mode & 27.000 & 14.000 & 66.000 \\
Std. Deviation & 4.376 & 2.257 & 10.165 \\
Minimum & 8.000 & 5.000 & 31.000 \\
Maximum & 30.000 & 15.000 & 75.000 \\
Sum & 6325.000 & 3225.000 & 15904.000 \\
\hline
\end{tabular}

Pada tabel 1 menunjukkan bawah pada variabel kompetensi pedagogik guru skor rata-rata sebesar 23,9 dengan skor maksimum 30 serta presentase sebesar 79, $9 \%$ hal ini menunjukkan bahwa kompetensi pedagogik guru dikategori sangat baik. Kemudian pada variabel profil karakteristik awal guru memiliki skor rata-rata sebesar 12,170 dengan skor maksimum 15 dserta tingkat presentase sebesar $81,13 \%$ yang menunjukkan bahwa profil karakteristik awal guru dikategorikan sangat baik. Selanjutnya pada variabel pengetahuan pedagogik guru skor rata-rata sebesar 60,015 dengan skor maksimum 75 serta presentase sebesar 80,02\% menunjukkan bahwa pengatahuan pedagogik guru dapa dikategorikan sangat baik. Hal ini menunjukkan bahwa kompentensi pedagogik guru, profil karakteristik awal, serta pengetahuan pedagogik yang dimiliki guru sangat baik. Selanjutnya gambaran data boxplot, plot violin dan jiteer dari ketiga variabel disajikan pada gambar 1 berikut.

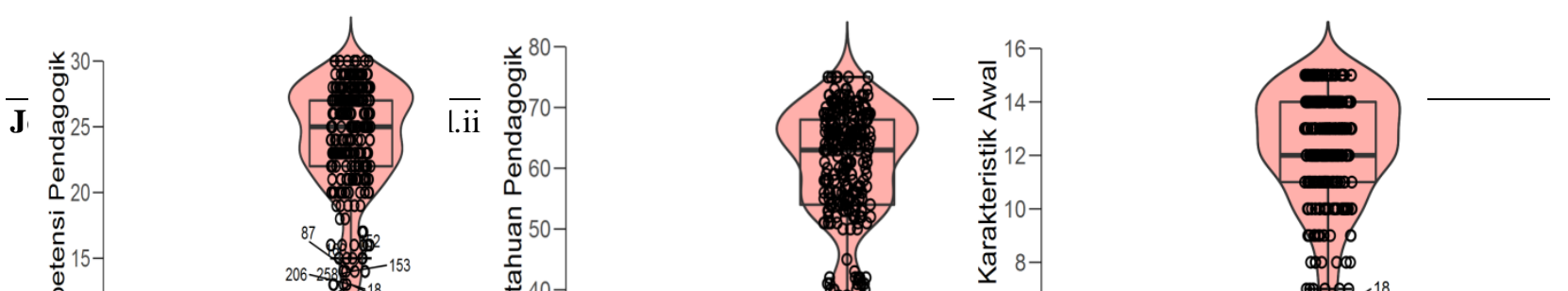


Gambar 1. Boxplot variabel kompetensi pedagogik, pengetahuan pedagogik, dan profil karakteristik awal

Berdasarkan gambar boxplot dapat dilihat pada kompetensi pedagogik sebaran skor cenderung banyak terkumpul pada interval skor 20-30 dengan nilai median 25 yang ditunjukkan dengan penyebaran data ke arah atas yang mengindikasikan bahwa kompetensi pendagogi guru sangat tinggi/sangat baik. Pada pengetahuan pedagogik arah jawaban cenderung banyak terkumpul pada interval skor 50-70 dengan nilai median 63 hal ini menunjukkan pengetahuan pedagogik responden sangat tinggi/sangat baik. Selanjutnya pada profil karakteristik awal menunjukkan penyebaran data terbanyak pada interval skor 10-15 dengan nilai median 12, menunjukkan bawah penyebaran data cenderung ke atas yang mengindikasikan bahwa profil karakteristik awal guru pada kondisi sangat tinggi/sangat baik. Berdasarkan gambaran boxplot tersebut dapat disimpulkan bahwa kompetensi pedagogik, pengetahuan pedagogik, dan profi karakteristik awal pada guru sangat baik.

Selanjutnya analisis mengenai hubungan atau keterkaitan dimensi pengetahuan pedagogik terhadap kompetensi pendagogi guru disajikan pada tabel 2 berikut.

Tabel 2. Keterkaitan Dimensi Pengetahuan Pedagogik terhadap Kompetensi Pedagogik

\begin{tabular}{cllrrrrrrr}
\hline Model & $\mathrm{R}$ & $\mathrm{R}^{2}$ & Adjusted $^{2}$ & RMSE & $\mathrm{R}^{2}$ Change & F Change & df1 & df2 & $\mathrm{p}$ \\
\hline 1 & 0.789 & 0.622 & 0.621 & 2.695 & 0.622 & 433.061 & 1 & 263 & $<.001$ \\
\hline
\end{tabular}

Berdasarkan tabel 2 dapat dilihat bahwa korelasi antara pengetahuan pedagogik dan kompetensi pedagogik tinggi dengan nlai (R) sebesar (0.789). Hal ini menunjukkan terdapat hubungan yang signifikan dimana semakin baik atau tingginya pengetahuan pedagogik guru maka akan semakian meningkat kompentensi pedagogik guru. Selanjutnya nilai $\mathrm{R}^{2}$ sebesar 0.621 menunjukkan bahwa dimensi pengetahuan pedagogik menyumbang $62,1 \%$ terhadap kompetensi pedagogik guru.

Tabel 3. Keterkaitan Dimensi Profil Karakteristik Awal terhadap Kompetensi Pedagogik

\begin{tabular}{cccccccccc}
\hline Model & $\mathrm{R}$ & $\mathrm{R}^{2}$ & $\begin{array}{c}\text { Adjusted } \\
\mathrm{R}^{2}\end{array}$ & RMSE & $\begin{array}{c}\mathrm{R}^{2} \\
\text { Change }\end{array}$ & F Change & df1 & df2 & $\mathrm{p}$ \\
\hline 1 & 0.706 & 0.499 & 0.497 & 3.104 & 0.499 & 261.679 & 1 & 263 & $<.001$ \\
\hline
\end{tabular}

Berdasarkan tabel 3 dapat dilihat bahwa korelasi antara profil karakteristik awal dan kompetensi pedagogik tinggi dengan nlai $(\mathrm{R})$ sebesar (0.706). Hal ini menunjukkan terdapat hubungan yang signifikan dimana semakin baik atau tingginya profil karakteristik awal guru maka akan semakin meningkat kompentensi pedagogik guru. Selanjutnya Nilai $\mathrm{R}^{2}$ sebesar 0.497 menunjukkan bahwa dimensi profil karakteristik awal menyumbang sebesar $49,7 \%$ terhadap kompetensi pedagogik guru.

Selanjutnya analisis mengenai jaringan atau keterkaitan antara ketiga variabel yaitu kompetensi pedagogik, pengetahuan pedagogik dan profil karakteristik awal disajikan pada tabel 4 berikut.

Tabel 4. Analisis Jaringan Ketiga Variabel

\begin{tabular}{llll}
\hline & \multicolumn{3}{c}{ Network } \\
\cline { 2 - 4 } Variable & Betweenness & Closeness & Strength \\
\hline
\end{tabular}


Tabel 4. Analisis Jaringan Ketiga Variabel

\begin{tabular}{lccc}
\hline & \multicolumn{3}{c}{ Network } \\
\cline { 2 - 4 } \multicolumn{1}{c}{ Variable } & Betweenness & Closeness & Strength \\
\hline KPD (kompetensi pedagogik) & 1.155 & 1.141 & 1.121 \\
PKA (profil karakteristik awal) & -0.577 & -0.723 & -0.799 \\
PPD (pengetahuan pedagogik) & -0.577 & -0.418 & -0.323 \\
\hline
\end{tabular}

Pada tabel 4 menunjukkan analisis jaringan jalan variabel yang saling terikat melihat suatu gambaran interaksi dan hubungan yang selalu terjadi antara variabel kompetensi pedagogik, pengetahuan pendagogi dan profil karakteristik awal dalam suatu kondisi dalam diri guru. Berdasarkan data menunjukkan keterkaitan antara variabel pengetahuan pedagogik dan profil karakteristik awal terhadap kompetensi pedagogik memilki kesaamaan sebesar -0,577. Kemudian secara kedekatan (closeness) profil karakteristik awal memilki hubungan yang lebih dekat dengan kompetensi pedagogik sebesar -0,723 sedangkan pengetahuan pedagogik memiliki kedekatan hubungan sebesar -0,418. Kemudian berdasarkan kekuatan jaringan (strength) menunjukkan bahwa profil karakteristik awal memiliki keterkaitan lebih kuat dengan kompetensi pedagogik sebesar -0,799 sedangkan pengetahuan pedagogik memiliki kekuatan jaringan sebesar $-0,323$. Selanjutnya visualisasi dari analisis jaringan ke tiga varibael disajikan pada gambar berikut.

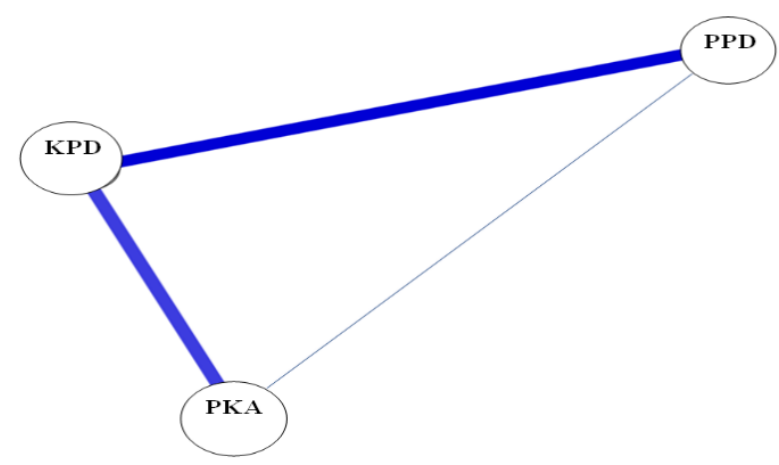

Gambar 2. Analisis jaringan (network) variabel kompetensi pedagogik, pengetahuan pedagogik, dan profil karakteristik awal

Pada gambar 2 menunjukkan bahwa kompetensi pedagogik memiliki hubungan atau jaringan yang kuat dengan dimensi pengetahuan pedagogik yang di ilustrasikan melalui garis biru yang menghubungkan keduanya. Kemudian kompetensi juga memiliki keterkaitan atau jaringan yang kuat dengan profil karakteristik awal yang di tunjukkan melalui garis biru tebal yang menghubungkan kedua dimensi ini. Untuk kedekatan hubungan dimensi profil karakteristik awal memiliki hubungan yang erat dengan kompetensi atau kemampuan pedagogik yang ditunjukkan melalui posisi PKA lebih dekat dibandingkan PPD namun keuduanya memiliki kekuatan atau jaringan yang kuat terhadap kompetensi pedagogik serta memiliki masingmasing hubungan memiliki timbal balik. Sedangkan dimensi pengetahuan pendagogi memiliki hubungan atau jaringan yang tidak kuat yang ditandai dengan garis biru tipis yang menghubungkan kedua dimensi tersebut.

Hasil dari deskripsi data menujukkan secara rata-rata kompetensi pendagogigik guru sangat baik dengan presentase sebesar 79, $9 \%$. Hal ini menujukkan bahwa guru sudah mampu memahami dan melaksanakan proses pembelajaran dengan baik. Dalam hal ini guru sudah mampu mengidentifikasi karakteristik belajar, mengelola kesempatan partisipasi dalam bentuk pengalaman belajar, mengelola permasalahan perilaku belajar, mengoptimalkan potensi dan kekurangan, serta guru dapat bertindakan sdukatif humanis kepada peserta didik. Dalam hal ini guru sudah memiliki kemampuan dalam mengelola pembelajaran peserta didik.

Hasil menunjukkan bahwa dimensi pengetahuan pedagogik menyumbang $62,1 \%$ terhadap kompetensi pedagogik guru. Dalam mengembangkan kompetensi pedagogik guru harus memilik pengetahuan pedagogik yang meliputi konsep pengetahuan filsafat pendidikan, penerapan psikologi perkembangan dan penerapan teori belajar. Pengetahuan sebagai pemahaman terhadap konsep dan penerapan pedagogik menjadi kapasitas dan kapabilitas guru dalam tugas profesionalnya (Widyastuti, 2016). Ketika guru memiliki pemahaman teoritis mengenai filsafat pendidikan, hakikat pendidikan, memahami berbagai teori perkembangan psikologi peserta didik, serta menguasai dan memahami berbagai teori belajar yang ada akan memudahkan guru untuk 
dapat mengaplikasikan teori yang telah dipelajari dan difahami ini dalam menjalan fungsi dan tugasnya dalam memberikan pembelajaran ke pada peserta didik dengan tepat. Artinya pemahaman guru mengenai teoritis dan pengetahuan pedagogik ini akan membantu mengoptimalkan pengembangan kompetensi pedagogik guru. Sehingga guru dapat melakukan tindakan dengan tepat sesuai dengan bekal ilmu pengetahuan yang telah dipelajari dan difahaminya (Kumala, et al., 2018; Putro, 2016).

Selanjutnya dimensi profil karakteristik awal menyumbang sebesar $49,7 \%$ terhadap kompetensi pedagogik guru. Sangat penting difahami profil karakteristik awal yang idealnya harus dimiliki seorang guru. Bahwa terdapat beberapa penanaman karakter awal dalam membangun diri guru sejati, profil karakterstik awal meliputi kemampuan mendasar guru yang mencakup kemampuan memaknai spiritualitas profesi atau makna nilai pekerjaan dalam dirinya, artinya seorang guru harus mampu memaknai dan memahami secara mendalam esensi profesi guru tidak hanya sekedar pelepas tanggung jawab namun juga sebagai wujud spiritualitas dalam diri dimana bentuk pertanggung jawaban tugas tidaknya kepada manusia namun juga kepada tuhan yang maha kuasa (Núñez-Canal, de Obesso, \& Pérez-Rivero, 2022; Susanto, et al., 2020). Kemudian guru memiliki kemampuan tindakan belajar, bertumbuh dan berkembang dalam kegiatan pengembangan diri dalam kemampuan literasi konten pengetahuan, pedagogikal dan teknologikal dan mengelola perubahan perilaku belajar peserta didik. Hal ini menunjukkan bahwa ketika seorang guru memiliki profil karakteristik awal yang baik akan memberikan pengaruh baik dalam pengembangan kompetensi pedagogik guru (Haryanti, 2016; Noviartati, 2015).

Guru harus mampu menginternalisasi berbagai nilai kehidupan dan spiritualitas dalam dirinya, mengembangkan hard skil dan soft skill serta memahami perkembangan pengalaman belajar peserta didik. Guru harus menguasai empat pilar dalam pembelajaran, yaitu belajar dengan mengetahui, belajar dengan melakukan, belajar untuk menjadi dirinya sebagai pribadi yang utuh, dan belajar untuk hidup bersama orang lain dengan menerima perbedaan, dan belajar untuk berkelanjutan dan tangguh agar dapat melaksanakan proses pembelajaran yang bermakna dan mengembangkan peserta didik menjadi individu yang memahami ipteks (Burbules, Fan, \& Repp, 2020; Combes, 2015; Liaqat, et al., 2021). Guru harus menguasai baik muatan disiplin ilmu, maupun muatan pedagogik, yang kemudian dikembangkan berdasarkan perkembangan ilmu pengetahuan dan teknologi terkini. Serta guru harus memahami karakteristik peserta didik dan mengenalinya dengan berbagai pendekatan, memahami materi baik dalam konten disiplin maupun pedagogis, dan mengembangkan kemampuan profesional secara berkelanjutan (Habibullah, 2012; Núñez-Canal, et al., 2022).

Dari penjelasan tersebut menunjukkan bahwa jika kompetensi pedagogik tidak dapat dipisahkan dengan dimensi pengetahuan pedagogik serta profil karakteristik awal hal ini dikarenakan kedua dimensi tersebut memiliki hubungan yang kuat dan timbal baik terhadap kemampuan pedagogik. Hal ini mengindikasikan bahwa untuk kemampuan pedagogik yang optimal maka diperlukan pengembangan pengetahuan pedagogik serta penanaman profil karaktersitik awal guru yang optimal.

\section{Simpulan}

Hasil pembahasan merumuskan bahwa kompetensi guru yang mencakup pengetahuan pedagogik serta profil karakteristik awal yang dimiliki guru pada kategori tinggi atau sangat baik. Kemudian dimensi pengetahuan pedagogik memiliki keterkaitan dengan kompetensi pedagogik dengan sumbangsih sebesar $62,1 \%$. Kemudian profil karakteristik awal guru memiliki sumbangsih sebesar $49,7 \%$ terhadap kompetensi pedagogik. Kompetensi pedagogik dan profil karaktersitik awal guru memberi kontribusi dalam pengembangan kompetensi pedagogik guru, kemudian kedua dimensi ini memiliki jaringan yang kuat untuk memebentuk kompetensi pedagogik guru, sehingga untuk mewujudkan kompetensi pedagogik yang optimal perlu dilakukan pengembangan pada dimensi pengetahuan pedagogik serta penanaman profil karakteristik awal dari guru. Guru sebagai komponen penting dalam proses pembelajaran harus terus mengembangkan ilmu pengetahuan dan teknologi yang selalu dinamis, mengembangkan keterampilan secara berkelanjutan, memahami esensi dan memakani profesi guru dengan baik, mengembangkan pemahaman perkembangan psikologis peserta didik, mengembangkan kreatifitas serta selalu melakukan inovasi dalam pembelajaran.

\section{Referensi}

Agustiani, R. (2015). Profil pengetahuan pedagogik konten mahasiswa calon guru matematika dalam melaksanakan pembelajaran dengan pendekatan PMRI. Jurnal Pendidikan Matematika RAFA, 1(2), 288305. 
Amalianita, B., Firman, F., \& Ahmad, R. (2021). Penerapan sistem pendidikan disentralisasi serta upaya peningkatan mutu layanan dengan pengembangan profesionalisme guru bimbingan konseling. JRTI (Jurnal Riset Tindakan Indonesia), 6(1), 9-14.

Antoninis, M., April, D., Barakat, B., Bella, N., D’Addio, A. C., Eck, M., . . McWilliam, A. (2020). All means all: An introduction to the 2020 Global Education Monitoring Report on inclusion. Prospects, 49(3), 103-109.

Astuti, T. A., \& Jailani, J. (2020). Kontribusi kompetensi guru matematika SMP terhadap prestasi belajar siswa. Jurnal Riset Pendidikan Matematika, 7(2), 241-253.

Burbules, N. C., Fan, G., \& Repp, P. (2020). Five trends of education and technology in a sustainable future. Geography and Sustainability, 1(2), 93-97.

Charoline, C., Lestari, D., Rahadian, C. M. j., \& Mahulette, A. R. (2020). Nilai Pengetahuan Pedagogik Bagi Calon Guru. Paper presented at the Seminar Nasional Ilmu Pendidikan dan Multi Disiplin 3 (SNIPMD 3). ISBN: 978-623-6566-35-0.

Combes, B. P. (2015). The United Nations decade of education for sustainable development (2005-2014): Learning to live together sustainably. Applied Environmental Education and Communication, 4(3), 215-219.

Habibullah, A. (2012). Kompetensi pedagogik guru. Edukasi, 10(3), 294376.

Haryanti, E. H. W. (2016). Profil Pedagogical Content Knowledge Mahasiswa Calon Guru Biologi. Bioma: Jurnal Ilmiah Biologi, 5(1).

Hopfenbeck, T. N., Lenkeit, J., El Masri, Y., Cantrell, K., Ryan, J., \& Baird, J.-A. (2018). Lessons learned from PISA: A systematic review of peer-reviewed articles on the programme for international student assessment. Scandinavian Journal of Educational Research, 62(3), 333-353.

Jalinus, N., \& Risfendra, R. (2020). Analisis Kemampuan Pedagogi Guru SMK Yang Sedang Mengambil Pendidikan Profesi Guru Dengan Metode Deskriptif Kuantitatif Dan Metode Kualitatif. INVOTEK: Jurnal Inovasi Vokasional Dan Teknologi, 20(1), 37-44.

Kienlin, S., Poitras, M. E., Stacey, D., Nytrøen, K., \& Kasper, J. (2021). Ready for SDM: evaluating a trainthe-trainer program to facilitate implementation of SDM training in Norway. [Article]. BMC Medical Informatics and Decision Making, 21(1). doi: 10.1186/s12911-021-01494-x

Kumala, V. M., Susilo, J., \& Susanto, R. (2018). Hubungan Pengetahuan Pedagogik Dengan Kompetensi Pedagogik Serta Perbedaannya Di Sekolah Negeri Dan Sekolah Swasta. Hub. Pengetah. Pedagog. dengan akaompetensi Pedagog, 1-23.

Lalo, K. (2018). Menciptakan generasi milenial berkarakter dengan Pendidikan karakter guna menyongsong era globalisasi. Jurnal Ilmu Kepolisian, 12(2), 8.

Liaqat, M., Hussain, M., Afzal, M., Altaf, M., Khan, S., Gilani, S. A., \& Liaqat, I. (2021). Efficacy of pedagogical framework in neonatal resuscitation skill learning in a resource-limited setting: a randomized controlled trial. [Article]. BMC Medical Education, 21(1). doi: 10.1186/s12909-021-02846-x

Maksum, A. (2010). Kualitas guru pendidikan jasmani di sekolah: Antara harapan dan kenyataan. Paper presented at the Makalah dipresentasikan dalam forum penelitian Balitbang Depdiknas.

Mundy, K., \& Manion, C. (2021). The Education for All Initiative and the Sustainable Development Goals: History and Prospects. Education and International Development: An Introduction, 57.

Musfah, J. (2021). Analisis Kebijakan Pendidikan: Pendidikan di Era Revolusi Industri 4.0: Prenada Media.

Mutadi, M., Mudofir, M., \& Munadi, M. (2021). Peran Manajemen Kepemimpinan, Pelatihan Dan Supervisi Terhadap Pedagogical Content Knowledge Di Madrasah. Jurnal Ilmiah Ekonomi Islam, 7(2), 638-647.

Noviartati, K. (2015). Profil Keterampilan Mengajar Mahasiswa Calon Guru Melalui Kegiatan Induksi Guru Senior. Jurnal Riset Pendidikan, 1(01), 57-64.

Núñez-Canal, M., de Obesso, M. D. L. M., \& Pérez-Rivero, C. A. (2022). New challenges in higher education: A study of the digital competence of educators in Covid times. [Article]. Technological Forecasting and Social Change, 174. doi: 10.1016/j.techfore.2021.121270

Permadi, D. S. (2020). Program Pengembangan Keprofesian Berkelanjutan Melalui Pendidikan Dan Pelatihan Guru Dalam Meningkatkan Kompetensi Profesional Guru Sekolah Dasar. Nusantara Education Review, 3(1), 23-34.

Prawira, Y. A., \& Nugraha, F. (2021). Peningkatan Kompetensi Pedagogik Guru Madrasah Melalui Pelatihan Partisipatif Secara Daring Berbasis Heuristik. Aksara: Jurnal Ilmu Pendidikan Nonformal, 7(2), 307-316.

Putro, S. C. (2016). Pengetahuan Pedagogik dan Keteknikan sebagai Prediktor Kemampuan Adaptasi Calon Guru pada Mahasiswa Jurusan Teknik Elektro FT UM. Teknologi dan Kejuruan: Jurnal teknologi, Kejuruan dan Pengajarannya, 39(1).

Ramberg, J. (2021). Global Education Monitoring Report 2021-Central andEastern Europe, the Caucasus and Central Asia-Inclusion and education: All means all.

Saragih, A. H. (2008). Kompetensi minimal seorang guru dalam mengajar. Jurnal Tabularasa, 5(1), 23-34. 
Siregar, N. H. (2020). Pengembangan Kualitas Pendidikan Di Indonesia Dilakukan Melalui Peningkatan Profesionalitas Guru. Jurnal Penelitian, Pendidikan dan Pengajaran: JPPP, 1(1), 38-48.

Sudrajat, J. (2020). Kompetensi guru di masa pandemi COVID-19. Jurnal Riset Ekonomi Dan Bisnis, 13(1), 100110.

Suhandani, D., \& Julia, J. (2014). Identifikasi kompetensi guru sebagai cerminan profesionalisme tenaga pendidik di Kabupaten Sumedang (kajian pada kompetensi pedagogik). Mimbar Sekolah Dasar, 1(2), 128141.

Susanto, R., Sofyan, H., Rozali, Y. A., Nisa, M. A., Umri, C. A., Nurlinda, B. D., . . Lestari, T. H. (2020). Pemberdayaan Kompetensi Pedagogik Berbasis Kemampuan Reflektif Untuk Peningkatan Kualitas Interaksi Pembelajaran. International Journal of Community Service Learning, 4(2), 125-138.

Undang-Undang. (No 20 Tahun 2005). Undang-undang Republik Indonesia No 20 Tahun 2005 Guru dan Dosen. Diambil dari:(http://sindikker. dikti. go. id/dok/UU/UUNo142005 (Guru\% 20\&\% 20Dosen). pdf), pada tanggal 27 Oktober 2021.

Vazquez-Lopez, V., \& Huerta-Manzanilla, E. L. (2021). Factors Related with Underperformance in Reading Proficiency, the Case of the Programme for International Student Assessment 2018. European Journal of Investigation in Health, Psychology and Education, 11(3), 813-828.

Widyastuti, M. (2016). Pengaruh Supervisi Kepala Sekolah dan Pengetahuan Pedagogik Terhadap Komitmen Profesi Guru. Faktor: Jurnal Ilmiah Kependidikan, 3(1), 19-28.

Yesi, A., Rahayu, S., \& Wahyuni, Y. S. (2021). Upaya Kepala Sekolah dalam Pengembangan Kompetensi Pedagogik Guru d SMA Negeri 2 Kinali Kabupaten Pasaman Barat. Jurnal Pendidikan Tambusai, 5(3), 6697-6707. 